\title{
Effect of an energy-dense diet on the clinical course of acute shigellosis in undernourished children
}

\author{
Ramendra N. Mazumder*, Hassan Ashraf, Syed S. Hoque, Iqbal Kabir, Naseha Majid, \\ Mohammad A. Wahed, George J. Fuchs and Dilip Mahalanabis \\ International Centre for Diarrhoeal Disease Research, Bangladesh (ICDDR, B) GPO Box 128, Dhaka 1000, Bangladesh
}

(Received 24 March 1998 - Revised 21 February 2000 - Accepted 21 March 2000)

\begin{abstract}
To date there have been few reports on the impact of dietary intervention on the clinical course of acute shigellosis. Current management of acute shigellosis is primarily focused on antibiotic therapy with less emphasis on nutritional management. In a randomised clinical trial, we examined the role of an energy-dense diet on the clinical outcome in malnourished children with acute dysentery due to shigellosis. Seventy-five children aged 12-48 months with acute dysentery randomly received either a milk-cereal formula with an energy density of $4960 \mathrm{~kJ} /$ 1 (test group) or a milk-cereal formula with energy of $2480 \mathrm{~kJ} / \mathrm{l}$ (control group) for $10 \mathrm{~d}$ in hospital. In both milk-cereal formulas, protein provided $11 \%$ energy. In addition, the standard hospital diet was offered to all children and all children received an appropriate antibiotic for $5 \mathrm{~d}$. The mean food intakes $(\mathrm{g} / \mathrm{kg}$ per $\mathrm{d})$ in the test and control groups were: 112 (SE 2.28) and 116 (SE 3.48) $(P=0 \cdot 16)$ on day $1 ; 118($ SE 2.72$)$ and $107($ SE 3.13$)(P=0.04)$ on day $5 ; 120$ (SE $2.25)$ and $100(\mathrm{SE} 3.83)(P=0.04)$ on day 10 . The mean energy intakes $(\mathrm{kJ} / \mathrm{kg}$ per d) in the test and control groups respectively were: 622 (SE 13.2) and 315 (SE 11.3) $(P<0.05)$ on day 1; 655 $($ SE 15.1) and 311 (SE 7.98) $(P<0.05)$ on day 5; $672($ SE 14.7) and 294 (SE 11.1) $(P<0.05)$ on day 10. The food and energy intakes were mostly from the milk-cereal diet. There was no difference between two groups in resolution of fever, dysenteric (bloody and or mucoid) stools, stool frequency and tenesmus. However, vomiting was more frequently observed among the test-group children during the first $5 \mathrm{~d}$ of intervention $(67 \% v .41 \%, P=0.04)$. There was an increase in the mean weight-for-age (\%) in the test group compared with the control group after the $10 \mathrm{~d}$ of dietary intervention $(6.2$ (SE 0.6) v. 2.7 (SE 0.4), $P<0.01)$. In addition, resolution of rectal prolapse was better $(26 \% v .8 \%, P=0.04)$ in the test group $v$. control group after $5 \mathrm{~d}$, and $13 \%$ v. $6 \%,(P=0.08)$ after $10 \mathrm{~d}$ of dietary intervention. Supplementation with a highenergy diet does not have any adverse effect on clinical course of acute shigellosis and reduces the incidence of rectal prolapse in malnourished children.
\end{abstract}

\section{Shigellosis: Malnutrition: Rectal prolapse: Children: Energy-dense diet}

Shigellosis is a major health problem in Bangladesh and in many other developing countries. Worldwide, it is estimated that shigellosis accounts for about $15 \%$ of diarrhoea-associated deaths in children below 5 years of age (Victoria et al. 1993). In Bangladesh, a death rate of 1.2 $\%$ has been reported in children with shigellosis attending a rural treatment centre (Black et al. 1980). In an urban setting, this value is higher, with a death rate of $3.5 \%$ in children aged 1-4 years, and 4.4\% in older children (Bennish et al. 1990). The complications of shigellosis are equally serious and include rectal prolapse, hyponatraemia, hypoglycaemia, hypoproteinaemia, haemolytic-uraemic syndrome and bacteraemia (Struelens et al. 1985; Bennish, 1991). Children who survive shigellosis develop malnutrition that may be due to loss of appetite, increased catabolism, and loss of nutrients in stools (Scrimshaw, 1977). Shigellosis is most prevalent among children with pre-existing malnutrition which deteriorates further (Briend et al. 1986; Katz, 1986). Growth retardation after diarrhoeal diseases (including shigellosis) has been documented in several studies (Martorell et al. 1975; Rowland et al. 1977; Tomkins, 1981; Black et al. 1984; Henry et al. 1987). Management of shigellosis is focused on antibiotic therapy with relatively less attention to the nutritional

\footnotetext{
* Corresponding author: Dr Ramendra N. Mazumder, present address GI Laboratory, Western General Hospital, Edinburgh EH4 2XU, Scotland, fax + 44 (0)131 537 1007, email rmazumder@ed.ac.uk
} 
aspects of the management. A recent study has shown that feeding a high-protein diet to children during the convalescence from shigellosis leads to greater catch-up growth (Kabir et al. 1993). However, energy intakes from standard hospital diets are often low for children with such a catabolic illness (Molla et al. 1983).

We performed the present study to test the effect of a diet with increased energy and protein content on the clinical course of shigellosis during the acute phase of illness. In addition, we aimed to evaluate the tolerance of such a diet by undernourished children with acute shigellosis.

\section{Subjects and methods}

The children were recruited after informed parental consent at the outpatient department of the International Centre for Diarrhoeal Disease Research, Dhaka, Bangladesh, which provides a service to more than 100000 patients per year for diarrhoeal illnesses (International Centre for Diarrhoeal Disease Research, Bangladesh, 1995). The children were boys or girls aged between 12 and 48 months with a history of blood or mucus in the stool for less than $72 \mathrm{~h}$, with $>20$ leucocytes per high-power field on stool microscopy, and a weight-for-age $<80 \%$ of National Center for Health Statistics median value (Hamil, 1977). Children treated at home with potentially effective drugs for shigellosis and those with obvious systemic illness such as pneumonia, sepsis, paralytic ileus, or children with kwashiorkor were excluded from the study. The Ethical Review Committee of the International Centre for Diarrhoeal Disease Research approved the study protocol. All children were admitted and studied in the metabolic ward of the hospital. An independent observer using permuted blocks of random numbers of variable length prepared a randomisation list. This randomisation list contained a serial number and a code for each of the diets (test or control). Serial numbered envelopes with a code for the specified diet according to the randomisation list were kept sealed until the child was ready to receive the diet. Children in both groups were offered our standard hospital diet, which consisted of rice, chicken curry and dal (lentil soup) for lunch and dinner; bread and egg for breakfast if appropriate for age or if the patient was accustomed to solid foods (Table 1). The intention was not to deviate from the existing hospital practice and standard patient care. Children in the test group were also offered an energy-dense milk-cereal diet (test diet, $4960 \mathrm{~kJ} / \mathrm{l}$ ) composed of milk powder, rice powder, sugar and soyabean oil, two hourly from 06.00 to 22.00 hours; control group children received a similar milk-cereal formula (control diet) delivering $2480 \mathrm{~kJ} / \mathrm{l}$ and offered on the same schedule. Mothers of breast-fed children were encouraged to continue breast-feeding ad libitum. Trained nutritionists closely observed all feeding and recorded intake. Actual food intake was calculated by subtracting the amount of food leftover from the amount offered, and energy intake was computed from the values obtained from the estimated laboratory value. No additional food from the parents was allowed during the study period.

Children were examined on admission and once daily during the study period. Rectal temperature, respiratory and pulse rate were recorded every $8 \mathrm{~h}$ until discharge. The maximum temperature on each study day was used for analysis. Microscopic examination of the stools and cultures of stool or rectal swab for Shigella spp. was performed in all patients. Blood was collected for estimation of serum electrolyte profile and complete blood count. Only children with Shigella spp. isolated from stools or rectal swabs were considered for analysis. All children were treated with oral nalidixic acid for $5 \mathrm{~d}$ except in suspected Shigella dysenteriae 1 infection or in confirmed nalidixic-acid-resistant cases in which children were treated with pivmecillinum orally for $5 \mathrm{~d}$.

\section{Analysis}

Differences in proportions were tested by $\chi^{2}$ test or Fisher's Exact Test when the predicted cell size was less than five. Relative risk and $95 \%$ CI were calculated. For continuous variables, mean values and standard deviations or $95 \% \mathrm{CI}$ were determined and the difference was tested by MannWhitney U test. A multiple logistic regression analysis was performed to control for possible confounding factors such as fever and nutrition status associated with the development of a rectal prolapse. Data were entered on a personal computer using StatPack Gold, version 3.1 (Walnock Associates, Minneapolis, MN, USA) and analysed using SPSS PC+ (SPSS Inc., Chicago, IL, USA). The National Center for Health Statistics statistical package (CDC, Atlanta, GA, USA) was used for anthropometric calculations.

Table 1. Nutrient composition of test and control diets*

\begin{tabular}{lcccc}
\hline & \multicolumn{2}{c}{ Test diet } & \multicolumn{2}{c}{ Control diet } \\
\cline { 2 - 5 } & Energy $(\mathrm{kJ} / \mathrm{kg})$ & Protein $(\mathrm{g} / \mathrm{kg})$ & Energy $(\mathrm{kJ} / \mathrm{kg})$ & Protein $(\mathrm{g} / \mathrm{kg})$ \\
\hline Energy-dense milk-cereal† & 4960 & $32 \cdot 5$ & - & - \\
Control milk-cereal ${ }^{\dagger}$ & - & - & 2480 & $16 \cdot 2$ \\
Bread & 2630 & $87 \cdot 4$ & 2630 & $87 \cdot 4$ \\
Rice (cooked) & 5200 & $19 \cdot 8$ & 5200 & $19 \cdot 8$ \\
Chicken curry & 9290 & 164 & 9290 & 164 \\
Dal (lentil) & 5090 & $16 \cdot 3$ & 5090 & $16 \cdot 3$ \\
Banana & 4180 & 14.2 & 4180 & $14 \cdot 2$ \\
\hline
\end{tabular}

* Analysed values of the foods are shown.

† For details of the ingredients see p. 776. 
Table 2. Clinical characteristics of patients at admission with acute shigellosis

\begin{tabular}{|c|c|c|c|c|c|c|c|c|}
\hline & \multicolumn{4}{|c|}{ Test $(n$ 36) } & \multicolumn{4}{|c|}{ Control ( $n$ 39) } \\
\hline & $n$ & $\%$ & Mean & SD & $n$ & $\%$ & Mean & SD \\
\hline Age (months) & & & $21 \cdot 2$ & 7 & & & $23 \cdot 8$ & 11 \\
\hline Sex & & & & & & & & \\
\hline Male & 23 & 64 & & & 25 & 64 & & \\
\hline Female & 13 & 36 & & & 14 & 36 & & \\
\hline Weight-for-age (\%) & & & $70 \cdot 2$ & 6 & & & $69 \cdot 3$ & 7 \\
\hline Temperature $>37.9^{\circ} \mathrm{C}$ & 11 & 31 & & & 14 & 36 & & \\
\hline Duration of dysentery $(\mathrm{h})$ & & & 61 & 27 & & & 67 & 29 \\
\hline No. of stools in previous $24 \mathrm{~h}$ & & & 17 & 8 & & & 16 & 7 \\
\hline Anorexia & 29 & 81 & & & 33 & 85 & & \\
\hline Vomiting & $31^{*}$ & 86 & & & 26 & 67 & & \\
\hline Straining during defecation & 24 & 67 & & & 30 & 77 & & \\
\hline Rectal prolapse & 10 & 28 & & & 8 & 21 & & \\
\hline
\end{tabular}

Mean value was significantly different from that of control group: ${ }^{\star} P=0.04$.

† Expressed as a percentage of the median value of the National Center for Health Statistics (Hamil, 1977).

\section{Results}

Seventy-five children with culture-proven Shigella infection were studied; thirty-six of these received the test diet and thirty-nine received the control diet. Children who did not grow any Shigella spp. on their stool culture on admission were excluded from the analysis. On admission, both groups were comparable with regard to age, sex, breast-feeding status, fever, duration of dysentery, stool frequency, tenesmus, and rectal prolapse (Table 2). However, vomiting that persisted for subsequent $5 \mathrm{~d}$ of the study was more frequent in the test group on admission. Laboratory measurements including serum protein, serum $\mathrm{Na}^{+}$concentration, packed cell volume, total blood count and Shigella spp. in stool culture were also comparable (Table 3). Of the whole group, $33 \%$ were febrile, $82 \%$ were anorectic by history, and $76 \%$ had a history of vomiting. Straining during defecation occurred in $72 \%$ of cases and $24 \%$ of the children presented with a rectal prolapse. Shigella flexneri was the predominant species (53\% of cases) isolated, followed by Shigella dysenteriae 1 ( $40 \%$ of cases).

The mean food intake $(\mathrm{g} / \mathrm{kg}$ per d) in the test and control groups respectively was: 112 (SE 2.28) and 116 (SE 3.48) $(P=0 \cdot 16)$ on day $1,118(\mathrm{SE} 2 \cdot 72)$ and $107(\mathrm{SE} 3 \cdot 13)(P=$ $0 \cdot 04)$ on day 5, and 120 (SE 2.25) and 100 (SE 3.83) $(P=$
$0 \cdot 04)$ on day 10 . The mean energy intake $(\mathrm{kJ} / \mathrm{kg}$ per $\mathrm{d})$ in the test and control groups respectively was: 622 (SE 13.2) and $315(\mathrm{SE} 11.3)(P<0.05)$ on day 1, $655(\mathrm{SE} 15 \cdot 1)$ and 311 (SE 7.98) $(P<0.05)$ on day 5, $672($ SE 14.7$)$ and 294 (SE 11.1$)(P<0.05)$ on day 10 . Intake of energy was mostly from the milk-cereal diet, and only a small amount was from the standard hospital diet. The resolution of fever, decrease in stool frequency and improvements in stool character were similar between the two groups. However, there was an increase in the mean weight-for-age (\%) in the test group compared with the control group after the $10 \mathrm{~d}$ of dietary intervention (6.2 (SE 0.6) v. 2.7 (SE 0.4); $P<0.01$ ). A higher prevalence of vomiting in the test-group children persisted for the first $5 \mathrm{~d}$ of intervention but was similar between the test and control groups subsequently. Straining during defecation improved similarly between the groups (Table 4). One child in each group developed abdominal distension that lasted for $24-36 \mathrm{~h}$. On admission, rectal prolapse was identified in eighteen patients, of whom ten were in the test group and eight in the control group. After $5 \mathrm{~d}$ of dietary intervention, the number of children with rectal prolapses was only three in the test group compared with ten in the control group (Odds ratio 3.79; $95 \% \mathrm{CI}$ $0 \cdot 95,15 \cdot 11)$. After controlling for the effect of fever and nutritional status (weight-for-height) through multiple logistic regression, the odds of having rectal prolapse in

Table 3. Packed cell volume, total leucocyte count, serum sodium and stool pathogens of the children with acute shigellosis

\begin{tabular}{|c|c|c|c|c|c|c|}
\hline & \multicolumn{3}{|c|}{ Test $(n$ 36) } & \multicolumn{3}{|c|}{ Control (n 39) } \\
\hline & Mean & SD & No. of cases & Mean & SD & No. of cases \\
\hline Packed cell volume (\%) & 36 & 3 & & 35 & 1 & \\
\hline Total leucocyte count $\left(\times 10^{9} / \mathrm{l}\right)$ & 14.7 & 6 & & $14 \cdot 2$ & 5 & \\
\hline Serum sodium $(\mathrm{mmol} / \mathrm{l})$ & 131 & 4 & & 132 & 4 & \\
\hline \multicolumn{7}{|l|}{ Shigella spp. isolated } \\
\hline S. dysenteriae type 1 & & & 12 & & & $18^{*}$ \\
\hline S. flexneri & & & 22 & & & 18 \\
\hline S. boydii & & & 0 & & & 2 \\
\hline S. sonnei & & & 1 & & & 0 \\
\hline S. dysenteriae type $2-10$ & & & 1 & & & 1 \\
\hline
\end{tabular}

Value was not significantly different from test group: ${ }^{\star} P>0.05$. 
Table 4. Changes in clinical characteristics after dietary intervention in children with acute shigellosis

\begin{tabular}{|c|c|c|c|c|c|c|c|c|c|c|c|}
\hline & \multicolumn{4}{|c|}{ Test $(n$ 36) } & \multicolumn{4}{|c|}{ Control (n 39) } & \multirow[b]{2}{*}{$P$} & \multirow[b]{2}{*}{$\mathrm{RR}$} & \multirow[b]{2}{*}{$95 \% \mathrm{Cl}$} \\
\hline & $n$ & $\%$ & Mean & SD & $n$ & $\%$ & Mean & SD & & & \\
\hline \multicolumn{12}{|c|}{ Fever $\left(>38^{\circ} \mathrm{C}\right)$} \\
\hline Day 5 & 5 & 14 & & & 4 & 10 & & & 0.89 & 0.74 & $0.21,2.54$ \\
\hline Day 10 & 1 & 3 & & & 3 & 8 & & & 0.66 & 2.77 & $0.30,25.43$ \\
\hline \multicolumn{12}{|c|}{ Stool character (free of blood) } \\
\hline Day 5 & 22 & 61 & & & 31 & 80 & & & 0.13 & 0.53 & $0.25,1.11$ \\
\hline Day 10 & 30 & 83 & & & 33 & 84 & & & 0.86 & 0.92 & $0.33,2.60$ \\
\hline \multicolumn{12}{|c|}{ Stool frequency/24 h } \\
\hline Day 5 & & & $8 \cdot 6$ & 1 & & & $8 \cdot 1$ & 2 & & & \\
\hline Day 10 & & & $3 \cdot 8$ & 1 & & & 3.7 & 1 & & & \\
\hline \multicolumn{12}{|c|}{ Vomiting (yes) } \\
\hline Day 5 & 24 & 67 & & & 16 & 41 & & & 0.04 & 0.62 & $0.40,0.96$ \\
\hline Day 10 & 5 & 14 & & & 6 & 15 & & & 0.88 & $1 \cdot 11$ & $0.37,3.32$ \\
\hline \multicolumn{12}{|c|}{ Abdominal distension (yes) } \\
\hline Day 5 & 1 & 3 & & & 1 & 3 & & & 0.5 & 0.92 & $0.06,14 \cdot 22$ \\
\hline Day 10 & 0 & & & & 0 & & & & & & \\
\hline \multicolumn{12}{|c|}{ Straining (yes) } \\
\hline Day 5 & 24 & 67 & & & 20 & 51 & & & 0.26 & 0.77 & $0.52,1.13$ \\
\hline Day 10 & 8 & 22 & & & 10 & 26 & & & 0.93 & $1 \cdot 15$ & $0.51,2.60$ \\
\hline \multicolumn{12}{|c|}{ Rectal prolapse (yes) } \\
\hline Day 5 & 3 & 8 & & & 10 & 26 & & & 0.04 & 3.08 & $0.92,10.32$ \\
\hline Day 10 & 2 & 6 & & & 8 & 13 & & & 0.08 & 3.69 & $0 \cdot 84,16 \cdot 25$ \\
\hline \multicolumn{12}{|c|}{ Serum sodium (mmol/l) } \\
\hline Day 5 & & & 134 & 4 & & & 133 & 5 & 0.16 & & \\
\hline Day 10 & & & 135 & 3 & & & 135 & 3 & 0.56 & & \\
\hline
\end{tabular}

$\mathrm{RR}$, relative risk.

the control group compared with the test group was 7.2 (95 $\%$ CI $1 \cdot 3,41)$.

\section{Discussion}

In our study, the energy intake in the control group was similar to that observed in previous studies done at the International Centre for Diarrhoeal Disease Research, Bangladesh (Henry et al. 1987). However, supplementary feeding with a source of concentrated energy resulted in a greater increase in the energy intake in malnourished children with shigellosis. During the study period, we did not observe any complications of shigellosis such as toxic megacolon, haemolytic uraemic syndrome, hypoglycaemia and hyponatraemia in any children (Struelens et al. 1985; Bennish, 1991). In addition, none of the patients had any clinical dehydration that required intervention. However, rectal prolapse was common among the children upon admission to the hospital. The mechanism of rectal prolapse in shigellosis is unclear. Pelvic floor weakness as a cause of rectal prolapse has been hypothesised as being due to the traction injury of the pudendal nerve (Mackle \& Parks, 1986). Pelvic floor weakness or laxity of the anal sphincter due to poor muscle mass may be a possibility in malnourished children. There was no prolongation of the duration of illness in the test group who received an energydense diet as compared with the control group. Resolution of fever, improvement in stool characters, and decrease in stool frequency were similar between the two groups. Vomiting was higher in the test group from the beginning of the study and persisted for first $5 \mathrm{~d}$ of the study. Straining during defecation is a frequent feature of shigellosis particularly when associated with Shigella dysenteriae 1 . In the present study, tenesmus was evident in most children and did not improve significantly with dietary intervention either in the test or control group. However, the incidence of rectal prolapse, usually associated with severe illness (World Health Organization, 1994), was significantly lower in the test group after controlling fever and nutrition status. The observed difference in the proportion of children with a rectal prolapse after $5 \mathrm{~d}$ of treatment is most likely to be related to the nutritional improvement in the test group compared with the control group children. From this study, we conclude that concentrated-energy feeds do not have any harmful effect on clinical symptoms. On the contrary, the energy-dense diet improved nutritional status and reduction in the incidence of rectal prolapse.

\section{Acknowledgements}

This research was supported by Swiss Development Cooperation and the International Centre for Diarrhoeal Disease Research, Bangladesh (ICDDR, B): Centre for Health and Population Research. The ICDDR, B is supported by countries and agencies which share its concern for the health problems of developing countries. Current donors include: the aid agencies of the governments of Australia, Bangladesh, Belgium, Canada, China, Denmark, Germany, Japan, the Netherlands, Norway, Republic of Korea, Saudi Arabia, Sweden, Switzerland, the UK and the USA; international organisations including the Arab Gulf Fund, Asian Development Bank, International Atomic Energy Centre, the United Nations International Children's Emergency Fund (UNICEF), the United Nations Development Program (UNDP), the United 
Nations Population Fund (UNFPA) and the World Health Organization (WHO); private foundations including Child Health Foundation, Ford Foundation, Population Council, Rockefeller Foundation and the Sasakawa Foundation; and private organisations including American Express Bank, Bayer A.G., CARE, Family Health International, Helen Keller International, the Johns Hopkins University, Macro International, New England Medical Center, Procter Gamble, RAND Corporation, SANDOZ, Swiss Red Cross and the University of Alabama at Birmingham, AL, USA, the University of Iowa Ames, IA, USA, and others.

\section{References}

Bennish ML (1991) Potentially lethal complications of shigellosis. Review of Infectious Disease 13, Suppl. 4, S319-S324.

Bennish ML, Harris JR, Wojtyniak BJ \& Struelens M (1990) Death in shigellosis: incidence and risk factors in hospitalised patients. Journal of Infectious Disease 161, 500-506.

Black RE, Brown KH \& Becker S (1984) Effects of diarrhoea associated with specific enteropathogens on the growth of children in rural Bangladesh. Paediatrics 73, 799-805.

Black RE, Merson MH, Rahman ASMM, Yunus M, Alim ARMA, Huq MI, Yolken RH \& Curlin GT (1980) A two-year study of bacterial, viral, and parasitic agents associated with diarrhoea in rural Bangladesh. Journal of Infectious Disease 142, 660-664.

Briend A, Dykewicz C, Graven K, Mazumder RN, Wojtyniak B \& Bennish M (1986) Usefulness of nutritional indices and classification in predicting death of malnourished children. British Medical Journal 293, 373-375.

Hamil PVV (1977) NCHS Growth Curve for Children birth-18 years, United States, DHEW publication no. (PHS) 78-165, Vital and Health Statistics, series 11, no.165. Hyattsville, MD: National Center for Health Statistics

Henry FJ, Alam N, Aziz KMS \& Rahaman MM (1987) Dysentery not watery diarrhoea is associated with stunting in Bangladeshi children. Human Nutrition: Clinical Nutrition 41C, 243-249.

International Centre for Diarrhoeal Disease Research, Bangladesh (1994) Annual Report Dhaka: ICDDR, B.
Kabir I, Malek MA, Mazumder RN \& Mahalanabis D (1993) Rapid catch-up growth of children fed a high protein-diet during convalescence from shigellosis. American Journal of Clinical Nutrition 57, 441-445.

Katz SL (1986) The burden of disease resulting from diarrhoea. In New Vaccine Development: Establishing Priorities. Diseases of Importance in Developing Countries, pp. 165 [SL Katz, editors]. Washington, DC: National Academy Press.

Mackle EJ \& Parks TG (1986) The pathogenesis and pathophysiology of rectal prolapse and solitary rectal prolapse syndrome. Clinical Gastroenterology 15, 985-1002.

Martorell R, Yarbrough C, Lechtig A, Habicht JP \& Klein RE (1975) Diarrhoeal diseases and growth retardation in pre-school Guatemalan children. American Journal of Physiological Anthropology 43, 341-346.

Molla AM, Molla A, Sarker SA \& Rahaman MM (1983) Food intake during and after recovery from diarrhoea in children. In Diarrhoea and Malnutrition: Interactions, Mechanisms and Interventions, pp. 155-160 [LC Chen and NS Scrimshaw, editors]. New York, NY: Plenum Press.

Rowland MGM, Cole TJ \& Whitehead RG (1977) A quantitative study into the role of infection in determining nutritional status in Gambian village children. British Journal of Nutrition 37, 441-450.

Scrimshaw NS (1977) Effect of infection on nutrient requirements. American Journal of Clinical Nutrition 30, 1536-1544.

Struelens MJ, Patte D, Kabir I, Salam MA, Nath SK \& Butler T (1985) Shigella septicaemia: prevalence, presentation, risk factors and outcome. Journal of Infectious Disease 152, 784790.

Tomkins A (1981) Nutritional status and severity of diarrhoea among pre-school children in rural Nigeria. Lancet 1, 860-862.

Victoria CG, Huntly SRA, Fuchs SC \& Barrows FC (1993) International difference in clinical patterns of diarrhoeal deaths: a comparison of children from Brazil, Senegal, Bangladesh, and India. Journal of Diarrhoeal Disease Research 11, 25-29.

World Health Organization (1994) Programme for the Control of Diarrhoeal Diseases. The Management of Bloody Diarrhoea in Young Children, WHO/CDD/94.49. Geneva: WHO. 